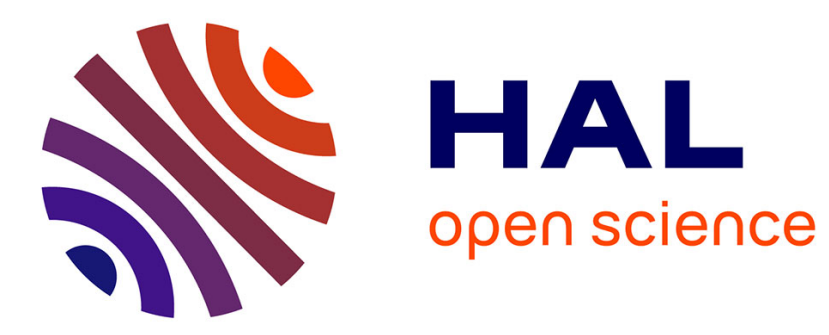

\title{
Low-spin Fe in silicate perovskite and a possible layer at the base of the lower mantle
}

C. Mccammon, L. Dubrovinsky, O. Narygina, I. Kantor, X. Wu, K. Glazyrin, I. Sergueev, A.I. Chumakov

\section{- To cite this version:}

C. Mccammon, L. Dubrovinsky, O. Narygina, I. Kantor, X. Wu, et al.. Low-spin Fe in silicate perovskite and a possible layer at the base of the lower mantle. Physics of the Earth and Planetary Interiors, 2010, 180 (3-4), pp.215. 10.1016/j.pepi.2009.10.012 . hal-00644709

\section{HAL Id: hal-00644709 \\ https://hal.science/hal-00644709}

Submitted on 25 Nov 2011

HAL is a multi-disciplinary open access archive for the deposit and dissemination of scientific research documents, whether they are published or not. The documents may come from teaching and research institutions in France or abroad, or from public or private research centers.
L'archive ouverte pluridisciplinaire HAL, est destinée au dépôt et à la diffusion de documents scientifiques de niveau recherche, publiés ou non, émanant des établissements d'enseignement et de recherche français ou étrangers, des laboratoires publics ou privés. 


\section{Accepted Manuscript}

Title: Low-spin $\mathrm{Fe}^{2+}$ in silicate perovskite and a possible layer at the base of the lower mantle

Authors: C. McCammon, L. Dubrovinsky, O. Narygina, I.

Kantor, X. Wu, K. Glazyrin, I. Sergueev, A.I. Chumakov

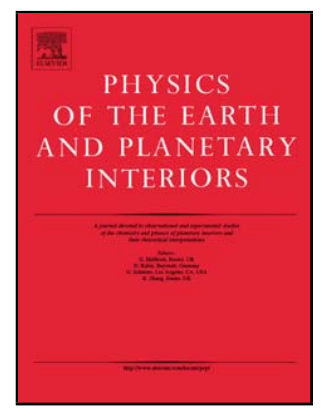

PII:

S0031-9201(09)00222-2

DOI:

doi:10.1016/j.pepi.2009.10.012

Reference:

PEPI 5220

To appear in: $\quad$ Physics of the Earth and Planetary Interiors

Received date: $\quad$ 2-6-2009

Revised date: 6-10-2009

Accepted date: $\quad$ 29-10-2009

Please cite this article as: McCammon, C., Dubrovinsky, L., Narygina, O., Kantor, I., Wu, X., Glazyrin, K., Sergueev, I., Chumakov, A.I., Low-spin $\mathrm{Fe}^{2+}$ in silicate perovskite and a possible layer at the base of the lower mantle, Physics of the Earth and Planetary Interiors (2008), doi:10.1016/j.pepi.2009.10.012

This is a PDF file of an unedited manuscript that has been accepted for publication. As a service to our customers we are providing this early version of the manuscript. The manuscript will undergo copyediting, typesetting, and review of the resulting proof before it is published in its final form. Please note that during the production process errors may be discovered which could affect the content, and all legal disclaimers that apply to the journal pertain. 
1 Low-spin $\mathrm{Fe}^{2+}$ in silicate perovskite and a possible layer at the base of the lower

2 mantle

C. McCammon ${ }^{1 *}$, L. Dubrovinsky ${ }^{1}$, O. Narygina ${ }^{1}$, I. Kantor ${ }^{1,2}, \mathrm{X} . \mathrm{Wu}^{1}, \mathrm{~K}$. Glazyrin $^{1}$,

5 I. Sergueev ${ }^{3}$, A. I. Chumakov ${ }^{3}$

6

Argonne, IL, 60439, USA

${ }^{1}$ Bayerisches Geoinstitut, Universität Bayreuth, D-95440 Bayreuth, Germany

${ }^{2}$ now at: University of Chicago, CARS, Building 434A, 9700 S. Cass Avenue,

${ }^{3}$ European Synchrotron Radiation Facility, BP 220, F-38043 Grenoble Cedex, France

1

*corresponding author

e-mail: catherine.mccammon@uni-bayreuth.de

$$
\text { fax: +49-(0)921-553769 }
$$

\section{Abstract}

We investigated the spin state of iron in $\mathrm{Mg}_{0.82} \mathrm{Fe}_{0.18} \mathrm{SiO}_{3}$ silicate perovskite using Mössbauer spectroscopy and nuclear forward scattering (NFS) at pressures up to 130 $\mathrm{GPa}$ and temperatures up to $1000 \mathrm{~K}$. Majorite starting material was loaded into diamond anvil cells in three separate experiments, and transformed to silicate perovskite through laser heating. We found, in agreement with previous work, the predominance of a component with high isomer shift ( $\sim 1 \mathrm{~mm} / \mathrm{s}$ relative to $\alpha$-Fe) and high quadrupole splitting (QS) (> $4 \mathrm{~mm} / \mathrm{s}$ ) in Mössbauer and NFS spectra up to 115 $\mathrm{GPa}$ at room temperature, and in accordance with previous work this component was assigned to intermediate-spin $\mathrm{Fe}^{2+}$. At higher pressures, the intensity of the high QS component in the silicate perovskite spectrum decreased, while the intensity of a new component with low isomer shift $(\sim 0 \mathrm{~mm} / \mathrm{s}$ relative to $\alpha-\mathrm{Fe})$ and low quadrupole splitting $(<0.5 \mathrm{~mm} / \mathrm{s})$ increased. This new component was assigned to low-spin $\mathrm{Fe}^{2+}$, and its intensity increased with both increasing pressure and increasing temperature: at $120 \mathrm{GPa}$ and $1000 \mathrm{~K}$ all $\mathrm{Fe}^{2+}$ was in the low-spin state. X-ray diffraction data showed well crystallised perovskite in all runs, and although the stable phase above $110 \mathrm{GPa}$ is expected to be post-perovskite, sluggish transition kinetics likely

33 preserved the perovskite phase in a metastable state. Our results combined with data 34 in the literature and thermodynamic and topological considerations suggest that there 
35 may be a region where silicate perovskite containing low-spin $\mathrm{Fe}^{2+}$ is stable, which

36 coincides with predicted pressure-temperature conditions near the $\mathrm{D}$ " layer.

37

38 Keywords: spin transition; D” layer; perovskite; post-perovskite; Mössbauer

39 spectroscopy, nuclear forward scattering

40 


\section{Introduction}

The base of the lower mantle shows many anomalous properties, a number of which have been explained by the transition of $(\mathrm{Mg}, \mathrm{Fe})(\mathrm{Si}, \mathrm{Al}) \mathrm{O}_{3}$ perovskite to a postperovskite structure (e.g., Hirose, 2006). Other properties, however, remain unexplained (e.g., large P-wave velocity discontinuities, the sharpness of the D" discontinuity in some regions, high electrical conductivity and the nature of ultralow velocity layers). One possibility that has been considered to account for these observations is lateral variations in chemistry at the base of the lower mantle (Hirose et al., 2006). However there is another mechanism that can change physical and chemical properties of minerals, namely spin-pairing transitions of iron. Such transitions were predicted to occur within the Earth's interior nearly 50 years ago, but only in the past few years has direct experimental evidence for such transitions at lower mantle conditions been reported. For $(\mathrm{Mg}, \mathrm{Fe}) \mathrm{O}$, both experimental and computational results confirm a high-spin to low-spin transition of $\mathrm{Fe}^{2+}$ that is expected to occur in the middle part of the lower mantle (e.g., Lin and Tsuchiya, 2008 and references therein). For $(\mathrm{Mg}, \mathrm{Fe})(\mathrm{Si}, \mathrm{Al}) \mathrm{O}_{3}$ perovskite, previous experimental results show a high-spin to intermediate-spin transition of $\mathrm{Fe}^{2+}$ that is expected to occur at the top of the lower mantle, with $\mathrm{Fe}^{2+}$ remaining in the intermediate-spin state throughout the bulk of the lower mantle (McCammon et al., 2008; Lin et al., 2008). $\mathrm{Fe}^{2+}$ in $(\mathrm{Mg}, \mathrm{Fe})(\mathrm{Si}, \mathrm{Al}) \mathrm{O}_{3}$ post-perovskite is also observed to be in the intermediatespin state (Lin et al., 2008). However Badro et al. (2004) observed that iron in $(\mathrm{Mg}, \mathrm{Fe}) \mathrm{SiO}_{3}$ perovskite was in the low-spin state above $120 \mathrm{GPa}$ at room temperature, although since the post-perovskite phase had not been discovered when the experiments were performed, the structure of the sample was not investigated. To address the question of whether low-spin $\mathrm{Fe}^{2+}$ is stable in silicate perovskite, we conducted a combined nuclear forward scattering (NFS) and conventional Mössbauer experiment on $(\mathrm{Mg}, \mathrm{Fe}) \mathrm{SiO}_{3}$ perovskite at high pressure and high temperature.

\section{Experimental methods}

The starting material for the present study was polycrystalline majorite with composition $\mathrm{Mg}_{0.82} \mathrm{Fe}_{0.18} \mathrm{SiO}_{3}\left(\sim 90 \%\right.$ enriched in ${ }^{57} \mathrm{Fe}$ ) (sample U1219; McCammon and Ross, 2003). The majorite sample was synthesised using a multianvil press; further details of synthesis conditions and sample characterisation can be found in McCammon and Ross (2003). We synthesised silicate perovskite from majorite using 
a laser-heated diamond anvil cell (DAC) in three different experiments, and carried out Mössbauer spectroscopy and/or NFS measurements over a range of different pressures and temperatures. The run conditions are summarised in Table 1.

Run \#1 was carried out at the European Synchrotron Radiation Facility (ESRF) during experiment HE-2750. The majorite sample was loaded together with a small ruby chip and a small (about $5 \mu \mathrm{m}$ in diameter) piece of gold (used as a pressure marker) with thin layers of $\mathrm{SiO}_{2}$ (which act as a thermal insulator during laser heating) into a Be gasket indented to $\sim 20 \mu \mathrm{m}$ thickness and drilled with $\mathrm{a} \sim 80 \mu \mathrm{m}$ hole. The gasket was mounted within a panoramic-type DAC, designed and constructed at Bayerisches Geoinstitut for nuclear inelastic scattering (NIS) experiments, and equipped with bevelled $120 \mu \mathrm{m}$ diameter culet gem-quality diamonds. The majorite sample was compressed to $33 \mathrm{GPa}$, and then heated with a double-sided near infrared laser $(\lambda=1064 \mathrm{~nm})$ at temperatures between 1800 and $2000 \mathrm{~K}$ to transform the sample to silicate perovskite. Pressure was increased incrementally, with annealing after each increase of pressure using an infrared laser at low power (temperature peak around $1500 \mathrm{~K}$ ) to relieve stress. The pressure was measured after each NFS spectrum using an online MAR CCD detector and calculated based on the equation of state of gold (Fei et al., 2007). NIS data were also collected during this experiment, but the results will be reported elsewhere.

Run \#2 was carried out mainly at Bayerisches Geoinstitut, but with laser heating at ESRF and X-ray diffraction collected at the Advanced Photon Source (APS), USA. The majorite sample with thin layers of $\mathrm{SiO}_{2}$ was loaded with a small ruby chip into a Re gasket preindented to about $30 \mu \mathrm{m}$ thickness and drilled with a $\sim 60 \mu \mathrm{m}$ diameter hole, and mounted in a four-pin modified Merrill-Bassett DAC with $120 \mu \mathrm{m}$ diameter culet gem-quality bevelled diamonds. The majorite sample was compressed in several steps to a pressure within the post-perovskite stability field, with annealing after each increase of pressure using an infrared laser at low power to relieve stress. At the highest pressure (145 $\pm 10 \mathrm{GPa}$ according to ruby fluorescence and the Raman shift of diamond) the sample was heated with a Nd:YLF laser $(\lambda=1064 \mathrm{~nm})$ to transform the sample to silicate perovskite. X-ray diffraction data collected on beamline IDD-13D at APS showed the sample to consist entirely of silicate perovskite at a pressure of $125 \pm 5 \mathrm{GPa}$ (based on the equation of state of silicate perovskite determined using the same methods; McCammon et al., 2008), with no evidence for a post-perovskite phase. 
Run \#3 was carried out primarily at ESRF during experiment HE-2750. Majorite was loaded together with a small ruby chip, a small piece of gold and layers of $\mathrm{SiO}_{2}$ into a Re gasket as for run \#1, and mounted in a four-pin modified Merrill-Bassett DAC with $200 \mu \mathrm{m}$ diameter culet gem-quality bevelled diamonds that was fitted with an external resistive heater (Dubrovinskaia and Dubrovinsky, 2003). The majorite sample was compressed directly to $120 \pm 5 \mathrm{GPa}$, where it was then heated with a near infrared laser to transform the sample to silicate perovskite. Subsequently the temperature was increased using the resistive heater, and the tension screws of the DAC were tightened to maintain the pressure at 120 GPa during heating.

Temperature was measured continuously using a S-type thermocouple mounted next to the diamonds, while pressure was measured both before and after the NFS data collection using ruby fluorescence corrected for temperature (Rekhi et al., 1999). A final NFS spectrum was collected after cooling to room temperature, and a Mössbauer spectrum was collected after return to Bayerisches Geoinstitut. High-resolution X-ray diffraction data were recorded on beam line ID09 at ESRF, and showed the sample to consist only of silicate perovskite plus a small amount of gold and $\mathrm{SiO}_{2}$ (Fig. 1). The pressure was calculated from the X-ray diffraction pattern to be $130 \pm 5 \mathrm{GPa}$ based on the gold equation of state (Fei et al., 2007). The higher pressure on cooling likely resulted from the tightening of the tension screws during heating to maintain the pressure.

${ }^{57} \mathrm{Fe}$ Mössbauer spectra were recorded at room temperature in transmission mode on a constant acceleration Mössbauer spectrometer with a nominal $370 \mathrm{MBq}{ }^{57} \mathrm{Co}$ high specific activity source in a $12 \mu \mathrm{m}$ thick Rh matrix. The methodology of highpressure Mössbauer measurements is further described in McCammon et al. (1992) and Kantor et al. (2004). The velocity scale was calibrated relative to $25 \mu \mathrm{m}$ thick $\alpha$ Fe foil using the positions certified for (former) National Bureau of Standards standard reference material no. 1541; line widths of $0.36 \mathrm{~mm} / \mathrm{s}$ for the outer lines of $\alpha$-Fe were obtained at room temperature. The dimensionless effective thickness for the majorite sample measured in air was $2\left(\sim 5 \mathrm{mg}\right.$ unenriched $\left.\mathrm{Fe} / \mathrm{cm}^{2}\right)$, while for the majorite/perovskite in the DAC it was $24\left(\sim 52 \mathrm{mg}\right.$ unenriched $\left.\mathrm{Fe} / \mathrm{cm}^{2}\right)$. Spectra took 4 to 10 days each to collect. Mössbauer spectra were fitted to Lorentzian lineshapes in the thin-absorber approximation using conventional constraints (equal quadrupole component widths and areas) using the commercially available fitting program NORMOS written by R.A. Brand (distributed by Wissenschaftliche Elektronik 
$143 \mathrm{GmbH}$, Germany). To explore the influence of thickness effects, we additionally used

144 a full transmission integral to fit the Mössbauer data, but found that hyperfine

145 parameters and relative areas were unchanged within experimental uncertainty.

146 NFS data were collected on beamline ID18 at the ESRF during operation in 4-

147 bunch mode, with the beam focused to ca. $8 \mu \mathrm{m} \times 13 \mu \mathrm{m}$ using a Kirkpatrick-Baez

148 mirror. Further details of the beamline are given in Rüffer and Chumakov (1996). All

149 of the NFS spectra in run \#3 and several of the spectra in run \#1 were taken with the

150 DAC in "vertical" geometry, i.e., with the plane of the gasket perpendicular to the X-

151 ray beam. For the NFS spectra in run \#1 that were taken in "horizontal" geometry, the

152 X-ray beam passed through the Be gasket before reaching the sample. Each NFS

153 spectrum took 1-2 hours to collect, and data were fitted using the program MOTIF

154 (Shvyd'ko, 2000).

155 High-resolution X-ray diffraction data were collected at beamline ID09 at ESRF

156 and beamline 13-ID-D at APS using the methods described in McCammon et al.

157 (2008). X-ray patterns were analysed by Rietveld refinement using the GSAS package

158 (Larsen and von Dreele, 1985).

159

160

\section{Results}

161 The NFS and Mössbauer spectra are illustrated in Figs. 2-4. In fitting the NFS

162 spectra, our goal was to extract only the parameters that could be robustly derived

163 from the data. We therefore restricted the number of sites to two, and varied only the

164 following parameters during the fit (number of parameters indicated in parentheses):

165 vertical scaling factor (1), Lorentzian broadening of all transitions (1), relative site

166 proportion (1), relative isomer shift between sites (1), and quadrupole splitting of each

167 site (2). Despite the limited parameter set, we were able to obtain reasonable fits for

168 all spectra. Our goal was the same in fitting the Mössbauer spectra, but the energy-

169 domain experiment enabled a larger number of parameters to be robustly determined

170 from the data (although energy resolution of NFS is formally ideal, in practice it is

171 limited by the time window of the 4-bunch mode $=704 \mathrm{~ns}$, providing $\Delta \mathrm{E}=\sim 0.1 \Gamma_{0}$ ).

172 The parameters determined from the Mössbauer spectra were: baseline (2); linewidth,

173 isomer shift, quadrupole splitting and relative area for each site (4 for each site).

174 The zero-pressure NFS spectrum of majorite (Fig. 2a) is dominated by quantum

175 beats with high frequency that arise from high-spin $\mathrm{Fe}^{2+}$ on the dodecahedral site,

176 which is seen in the zero-pressure Mössbauer spectrum as a quadrupole doublet with 
large splitting (Fig. 3a). The minor quadrupole doublets in the Mössbauer spectrum corresponding to high-spin $\mathrm{Fe}^{2+}$ on the octahedral site $(\sim 10 \%)$ and to high-spin $\mathrm{Fe}^{3+}$ (15-20\%) (Fig. 3a) cause small modulations of the dominant quantum beats in the NFS spectrum (Fig. 2a), but the overall structure of the spectrum remains the same. The transition from majorite to silicate perovskite causes a significant change in the NFS spectrum (Fig. 2c), which resembles those reported at similar conditions by McCammon et al. (2008). There are several contributions dominated by a mixture of high-spin $\mathrm{Fe}^{2+}$ and intermediate-spin $\mathrm{Fe}^{2+}$, both occupying the A site (McCammon et al., 2008). Since the high-spin $\mathrm{Fe}^{2+}$ contribution consists of more than one component, the use of only two components (one high-spin $\mathrm{Fe}^{2+}$ and one intermediate-spin $\mathrm{Fe}^{2+}$ ) to fit the spectrum produces only a moderately good fit to the data (Fig. 2c). However the fit improves as the relative proportion of the high-quadrupole splitting component assigned to intermediate-spin $\mathrm{Fe}^{2+}$ increases with pressure (Fig. 2d), and at $115 \mathrm{GPa}$ intermediate-spin $\mathrm{Fe}^{2+}$ accounts for nearly all of the spectrum (Fig. 2e). There is likely still a minor contribution from $\mathrm{Fe}^{3+}$, which for this composition is estimated to be $15-$ $20 \% \mathrm{Fe}^{3+} / \Sigma \mathrm{Fe}$ (McCammon et al., 2004). However previous work has shown that the proportion of $\mathrm{Fe}^{3+}$ does not change significantly with pressure (Jackson et al., 2005; McCammon et al., 2008), and the results of the current study are also consistent with this observation.

The Mössbauer spectrum for majorite in the DAC is significantly reduced in quality from the zero-pressure spectrum (Fig. 3a) due to solid angle reduction and absorption by the diamonds; however the dominant quadrupole doublet due to highspin $\mathrm{Fe}^{2+}$ on the dodecahedral site can still be resolved (Fig. 3b). After laser heating at $\sim 145 \mathrm{GPa}$ to transform the sample to silicate perovskite (structure confirmed by Xray diffraction), there is a clear change in the spectrum (Fig. 3c). The quadrupole splitting of the dominant doublet increases, consistent with the presence of intermediate-spin $\mathrm{Fe}^{2+}$, and a second component appears with significantly lower quadrupole splitting and isomer shift.

The presence of the low quadrupole splitting component is also observed when majorite is transformed through laser heating to silicate perovskite at $120 \mathrm{GPa}$ (Fig. 4). In the NFS spectra the presence of the high frequency quantum beats corresponding to intermediate-spin $\mathrm{Fe}^{2+}$ can still be observed (Fig. 4a), but they are superimposed on a relatively monotonous downward slope arising from a component with nearly zero quadrupole splitting. The proportion of the low quadrupole splitting 
211 component grows with increasing temperature (as seen by the disappearance of the

212 high frequency quantum beats), and at $1000 \mathrm{~K}$ the spectrum consists of only low

213 quadrupole splitting components. With the disappearance of intermediate-spin $\mathrm{Fe}^{2+}$ in

214 Figs. 4d and 4e, the presence of a minor amount of a second component with low

215 quadrupole splitting can be resolved, which likely corresponds to $\mathrm{Fe}^{3+}$. The

216 Mössbauer spectrum taken of the same sample at the same conditions as Fig. 4e

217 shows the low quadrupole splitting component as a singlet with extremely low isomer

218 shift (Fig. 3d), where the data scatter is too high for a Fe ${ }^{3+}$ component with $\sim 20 \%$

219 abundance to be resolved. The X-ray diffraction pattern taken of the same sample as

220 Fig. 3d shows only the Pbnm perovskite structure, confirming that the new component

221 arises only from an electronic transition (Fig. 1).

222 The variation of hyperfine parameters with pressure shows consistent trends for the

223 different components in the Mössbauer and NFS spectra (Fig. 5). The most notable

224 feature is the appearance above $120 \mathrm{GPa}$ of the component with low isomer shift and

225 quadrupole splitting. The proportion of this component increases correspondingly

226 with the decrease of intermediate-spin $\mathrm{Fe}^{2+}$, and there is a large difference in isomer

227 shift between this component and intermediate-spin $\mathrm{Fe}^{2+}$ (Fig. 5). The most plausible

228 assignment for this component is low-spin $\mathrm{Fe}^{2+}$ in the A site of silicate perovskite,

229 which is predicted to have both low isomer shift and low quadrupole splitting (e.g., Li

230 et al., 2006 and references therein). The proportion of low-spin $\mathrm{Fe}^{2+}$ in silicate

231 perovskite increases with both increasing pressure and increasing temperature (Fig.

$2326)$.

233 The assignment of the low quadrupole splitting component to low-spin $\mathrm{Fe}^{2+}$ is also

234 consistent with X-ray emission data which show a nearly complete disappearance of

235 the K $\beta$ ' satellite peak above $120 \mathrm{GPa}$, indicating the complete spin pairing of $3 d$

236 electrons (the residual intensity can be accounted for by a small amount of $\mathrm{Fe}^{3+}$ )

237 (Badro et al., 2004). Electrical conductivity data of $\mathrm{Mg}_{0.9} \mathrm{Fe}_{0.1} \mathrm{SiO}_{3}$ perovskite also

238 support the interpretation of low-spin $\mathrm{Fe}^{2+}$. The conductivity drop of more than two

239 orders of magnitude between 58 and $104 \mathrm{GPa}$ (Ohta et al., 2008) follows the expected

240 behaviour of a transition from two unpaired electrons (intermediate-spin $\mathrm{Fe}^{2+}$ ) to none

241 (low-spin $\mathrm{Fe}^{2+}$ ).

242 Low-spin $\mathrm{Fe}^{2+}$ has similar isomer shift and quadrupole splitting values to $\mathrm{Fe}^{3+}$ (Fig.

243 5), suggesting an alternative interpretation, namely that the low quadrupole splitting

244 component in Fig. 4 could be due to $\mathrm{Fe}^{3+}$. We consider such a possibility to be 
unlikely, however. The growth in intensity of the low quadrupole splitting component is proportional to the decrease of the intermediate-spin $\mathrm{Fe}^{2+}$ component, indicating that both take part in the transition. We can rule out that oxidation of $\mathrm{Fe}^{2+}$ to $\mathrm{Fe}^{3+}$ takes place as part of a chemical reaction, because we found the transition to be fully reversible with both pressure and temperature. It is also unlikely that intervalence charge transfer takes place, such as in $\mathrm{FeTiO}_{3}$ at high pressure $\left(\mathrm{Fe}^{2+}+\mathrm{Ti}^{4+} \leftrightarrow \mathrm{Fe}^{3+}+\right.$

$251 \mathrm{Ti}^{3+}$; Seda and Hearne, 2004) or $(\mathrm{Mg}, \mathrm{Fe}, \mathrm{Cr}) \mathrm{O}$ at high temperature $\left(\mathrm{Fe}^{2+}+\mathrm{Cr}^{3+} \leftrightarrow\right.$

$252 \mathrm{Fe}^{3+}+\mathrm{Cr}^{2+}$; Eeckhout et al., 2007), since there are no other species in our experiments 253 that could participate in coupled electron transfer. We can also rule out that the low 254 quadrupole splitting component could arise through the reaction $\mathrm{Fe}^{2+} \rightarrow \mathrm{Fe}^{3+}+\mathrm{Fe}^{0}$ as recently reported by Jackson et al. (2009) for laser-heated DAC experiments with $256(\mathrm{Mg}, \mathrm{Fe}) \mathrm{SiO}_{3}$ post-perovskite, because we found the transition to be fully reversible 257 with both pressure and temperature.

258 Previous NFS studies of $(\mathrm{Mg}, \mathrm{Fe}) \mathrm{SiO}_{3}$ and $(\mathrm{Mg}, \mathrm{Fe})(\mathrm{Si}, \mathrm{Al}) \mathrm{O}_{3}$ perovskite have 259 suggested that $\mathrm{Fe}^{3+}$ may undergo a pressure-induced spin transition (Jackson et al., 260 2005; Li et al., 2006). However the samples used in these studies contained 261 appreciable amounts of $\mathrm{Fe}^{3+}\left(\mathrm{Fe}^{3+} / \Sigma \mathrm{Fe} \sim 0.4\right.$ and 0.5 for the Jackson et al. and the Li 262 et al. samples, respectively) compared to the present study $\left(\mathrm{Fe}^{3+} / \Sigma \mathrm{Fe} \sim 0.15-0.2\right)$. Due 263 to the low intensity of the $\mathrm{Fe}^{3+}$ component in our data, we cannot resolve the 264 behaviour of $\mathrm{Fe}^{3+}$ unambiguously; hence the question of a spin transition in $\mathrm{Fe}^{3+}$ must 265 remain open. We note, however, that our conclusions are independent of the 266 behaviour of $\mathrm{Fe}^{3+}$, and they would not change if there were a spin transition in that 267 component.

268 Umemoto et al. (2008) suggested that sample annealing could enhance cation 269 diffusion and clustering of irons at high pressure, which would promote the stability 270 of low-spin $\mathrm{Fe}^{2+}$ in silicate perovskite. However since our experiment involving 271 external heating (run \#3) was conducted after the sample was laser heated at the same 272 pressure to synthesise silicate perovskite, the degree of cation order would not have 273 changed significantly during external heating. We therefore maintain that the spin 274 state recorded by our measurements at $120 \mathrm{GPa}$ and $1000 \mathrm{~K}$ represents close to 275 equilibrium for those conditions.

276 Recent computational studies of iron in silicate perovskite have reported a 277 pressure-induced high-spin to low-spin transition of $\mathrm{Fe}^{2+}$ in the A site (e.g., 278 Stackhouse et al., 2007; Bengston et al., 2008; Umemoto et al., 2008). Pressure 
determinations for the spin transition of silicate perovskite for the iron composition used in the present study range from $\sim 60 \mathrm{GPa}$ to $\sim 200 \mathrm{GPa}$, depending on parameters such as the exchange correlation method used and the atomic configuration of iron atoms in the supercell.

\section{Discussion}

Our results show that an intermediate- to low-spin transition involving $\mathrm{Fe}^{2+}$ on the A site takes place in $\mathrm{Mg}_{0.82} \mathrm{Fe}_{0.18} \mathrm{SiO}_{3}$ perovskite around $120 \mathrm{GPa}$. At this pressure the stable structure is expected to be post-perovskite (e.g., Hirose, 2006, and references therein); however the well known sluggish reaction kinetics of the perovskite to postperovskite phase transition (e.g., Mao et al., 2004) likely preserved the perovskite structure in a metastable state in our experiments. The important question is, therefore, whether silicate perovskite with low-spin $\mathrm{Fe}^{2+}$ is thermodynamically stable in any region of the phase diagram.

Our experimental data demonstrate that increasing temperature increases the stability of low-spin $\mathrm{Fe}^{2+}$ in silicate perovskite, reaching $100 \%$ low-spin $\mathrm{Fe}^{2+}$ at 1000 $\mathrm{K}$ and $120 \mathrm{GPa}$ (Fig. 6). It follows, therefore, that higher temperatures will preserve the low-spin state. If the phase boundary between perovskite and post-perovskite were shifted to higher pressures as a consequence of the intermediate- to low-spin transition of $\mathrm{Fe}^{2+}$ in silicate perovskite, there would be a region in which low-spin $\mathrm{Fe}^{2+}$ would be stable (Fig. 7). The slope of the phase boundary depends on the relative contribution of the entropy and volume terms to the free energy. Our observation that temperature stabilises the low-spin state relative to intermediate-spin $\mathrm{Fe}^{2+}$ implies that the $\mathrm{P}, \mathrm{T}$ slope of the transition in the perovskite field is negative, which means that the lowspin $\mathrm{Fe}^{2+}$ perovskite to post-perovskite phase boundary must have a less steep slope than the intermediate-spin $\mathrm{Fe}^{2+}$ perovskite to post-perovskite phase boundary based on Schreinemakers' Rules (Schreinemakers, 1916).

Our proposed phase diagram is consistent with existing data on the spin state of $\mathrm{Fe}^{2+}$ in silicate perovskite (Fig. 7). Lin et al. (2008) collected X-ray emission spectra for $\mathrm{Mg}_{0.6} \mathrm{Fe}_{0.4} \mathrm{SiO}_{3}$ perovskite at high pressure and temperature, and found a spin number $(S)$ close to one up to $3200 \mathrm{~K}$ at $108 \mathrm{GPa}$, which is consistent with the nuclear forward scattering data of McCammon et al. (2008) for $\mathrm{Mg}_{0.88} \mathrm{Fe}_{0.12} \mathrm{SiO}_{3}$ perovskite which showed intermediate-spin $\mathrm{Fe}^{2+}(S=1)$ to be present at $110 \mathrm{GPa}$ and $300 \mathrm{~K}$. Xray emission spectra of Badro et al. (2004) for $\mathrm{Mg}_{0.9} \mathrm{Fe}_{0.1} \mathrm{SiO}_{3}$ perovskite showed a 
313 spin number near one at $120 \mathrm{GPa}$, but near zero at 132 and $145 \mathrm{GPa}$. Lin et al. (2008)

314 suggest that an iron content below $\mathrm{x}_{\mathrm{Fe}}=0.4$ is likely below the percolation threshold

315 where iron-iron interactions could significantly influence the spin transition pressure;

316 hence no strong difference in spin behaviour would be predicted within the

317 composition range of data shown in Fig. 7.

318 The pressure interval over which low-spin $\mathrm{Fe}^{2+}$ perovskite could occur coincides

319 with predicted P,T conditions near D', raising the possibility of a layer at the base of

320 the lower mantle containing low-spin $\mathrm{Fe}^{2+}$. Lateral temperature variations change the

321 depth of the perovskite to post-perovskite transition, which would also affect the

322 relative abundance of different spin-state populations. In hot regions the intermediate-

323 to low-spin transition would occur well above the core-mantle boundary (CMB),

324 while in cold regions silicate perovskite with intermediate-spin $\mathrm{Fe}^{2+}$ would transform

325 directly to post-perovskite (Fig. 8). Hernlund et al. (2005) proposed that in cold

326 regions above the core-mantle boundary a double crossing of the perovskite to post-

327 perovskite transition could occur, accounting for double seismic discontinuities and

328 allowing an estimate of heat flow out of the core. In our scenario a double crossing

329 would still occur, but the layer of silicate perovskite adjoining the CMB would

330 contain low-spin $\mathrm{Fe}^{2+}$, not intermediate spin, which would influence physical and

331 chemical properties in that region.

332 The double-crossing model has been used in conjunction with geophysically

333 consistent estimates of deep mantle and inner core boundary temperatures to define

334 plausible ranges for the Clapeyron slope of the perovskite to post-perovskite transition

335 (Hernlund and Labrosse, 2007). In their analysis the higher estimates of the Clapeyron

336 slope from experiment and theory gave the best agreement with estimates of core

337 melting temperatures, while lower estimates such as those based on the gold pressure

338 scale (e.g., Hirose, 2006) were judged to be inconsistent. According to our results,

339 however, low-spin $\mathrm{Fe}^{2+}$ would increase the Clapeyron slope of the perovskite to post-

340 perovskite transition significantly (Fig. 7), favouring lower inner core boundary

341 temperatures and strengthening plausibility arguments for the double-crossing model

342 (Hernlund and Labrosse, 2007).

\section{5. Conclusions and outlook}

345 Our work has shown that low-spin $\mathrm{Fe}^{2+}$ is stable in silicate perovskite above $\sim 120$

$346 \mathrm{GPa}$, and that increasing temperature increases the stability of the low-spin state, 
347 raising the possibility of a layer containing low-spin $\mathrm{Fe}^{2+}$ silicate perovskite in the

348 lower mantle. The style of mantle convection is highly influenced by the chemical and

349 physical properties of materials at the $\mathrm{CMB}$; hence low-spin $\mathrm{Fe}^{2+}$ may play a role in

350 mantle dynamics. Unfortunately little is known about the properties of silicate

351 perovskite with low-spin $\mathrm{Fe}^{2+}$, which means that assessment of geophysical

352 implications must wait for the results of in situ studies, since spin transitions are

353 reversible with respect to both pressure and temperature. An initial wish list includes

354 measurements at conditions of D" of the spin state of iron in silicate perovskite as

355 well as the Clapeyron slope of the perovskite to post-perovskite transition (Fig. 7),

356 and the density change and sharpness of the intermediate- to low-spin transition in

357 silicate perovskite.

\section{Acknowledgements}

360 We acknowledge the European Synchrotron Radiation Facility for provision of 361 synchrotron radiation facilities (ID18 and ID09) and we would like to thank R. Rüffer and M. Hanfland for additional assistance. Use of the Advanced Photon Source

363 (beamline 13-ID-D) was supported by the U.S. Department of Energy, Office of

364 Science, Office of Basic Energy Sciences, under Contract No. DE-AC02-06CH11357, 365 and we would like to thank Vitali Prakapenka for additional assistance. The project 366 was partly supported by funds from the German Science Foundation (DFG) Priority 367 Programme SPP1236 under project Mc 3/16-1.

\section{References}

370 Badro, J., Rueff, J.P., Vanko, G., Monaco, G., Fiquet, G. and Guyot, F., 2004.

371 Electronic transitions in perovskite: Possible non-convecting layers in the lower

372 mantle. Science, 305: 383-386.

374 Bengtson, A., Persson, K. and Morgan, D., 2008. Ab initio study of the composition 375 dependence of the pressure induced spin crossover in perovskite $\left(\mathrm{Mg}_{1-\mathrm{x}}, \mathrm{Fe}_{\mathrm{x}}\right) \mathrm{SiO}_{3}$.

376 Earth and Planetary Science Letters, 265: 535-545.

378 Dubrovinskaia, N. and Dubrovinsky, L., 2003. Whole-cell heater for the diamond 379 anvil cell. Reviews of Scientific Instruments, 74: 3433-3437. 
381 Eeckhout, S.G., Bolfan-Casanova, N., McCammon, C.A., Klemme, S. and Amiguet, 382 E., 2007. XANES study of the oxidation state of $\mathrm{Cr}$ in lower mantle phases: periclase 383 and magnesium silicate perovskite. American Mineralogist, 92: 966-972.

Fei, Y. et al., 2007. Toward an internally consistent pressure scale. Proceedings of the

386 National Academy of Sciences of the United States of America, 104: 9182-9186.

Hernlund, J.W. and Labrosse, S., 2007. Geophysically consistent values of the perovskite to post-perovskite transition Clapeyron slope. Geophysical Research Letters, 34: doi:10.1029/2006GL028961, 2007.

Hernlund, J.W., Thomas, C. and Tackley, P.J., 2005. A doubling of the postperovskite phase boundary and structure of the Earth's lowermost mantle. Nature, 434: 882-886.

Hirose, K., 2006. Postperovskite phase transition and its geophysical implications. Reviews of Geophysics, 44: RG3001.

Hirose, K., Karato, S, Cormier, V.F., Brodholt, J.P. and Yuen, D.A., 2006. Unsolved problems in the lowermost mantle. Geophysical Research Letters, 33: doi:10.1029/2006GL025691.

402 perovskite up to $120 \mathrm{GPa}$. American Mineralogist, 90: 199-205. of iron in $(\mathrm{Mg}, \mathrm{Fe}) \mathrm{SiO}_{3}$ post-perovskite assemblages at Mbar pressures. Geophysical Research Letters, 36: doi:10.1029/2009GL037815.

411 Kantor, A.P., Jacobsen, S.D., Kantor, I.Y., Dubrovinsky, L.S., McCammon, C.A. and

412 Reichmann, H.J., 2004. Pressure-induced magnetization in FeO: evidence from

413 elasticity and Mössbauer spectroscopy. Physical Review Letters, 93: DOI:

414 10.1103/PhysRevLett.93.215502. 
416 Larsen, A.C. and von Dreele, R.B., 1985. General Structure Analysis System (GSAS).

417 Los Alamos National Laboratory Report LAUR B6-748, Los Alamos, USA.

419 Li, J., Sturhahn, W., Jackson, J.M., Struzhkin, V.V., Lin, J.F., Zhao, J., Mao, H.K. and 420 Shen, G., 2006. Pressure effect on the electronic structure of iron in $(\mathrm{Mg}, \mathrm{Fe})(\mathrm{Si}, \mathrm{Al}) \mathrm{O}_{3}$ 421 perovskite: a combined synchrotron Mössbauer and X-ray emission spectroscopy 422 study up to $100 \mathrm{GPa}$. Physics and Chemistry of Minerals, 33: 575-585.

Lin, J.-F. and Tsuchiya, T., 2008. Spin transition of iron in the Earth's lower mantle. Physics of the Earth and Planetary Interiors, 170: 248-259. V.V., Kubo, A., Zhao, J., McCammon, C. and Evans, W.J., 2008. Predominant intermediate-spin ferrous iron in lowermost mantle post-perovskite and perovskite. Nature Geoscience: 688-691.

Mao, W.L., Meng, Y., Shen, G., Prakapenka, V.B., Campbell, A.J., Heinz, D.L., Shu, J., Caracas, R., Cohen, R.E., Fei, Y., Hemley, R.J. and Mao, H.-k., 2005. Iron-rich silicates in the Earth's D" layer. Proceedings of the National Academy of Sciences, 102: 9751-9753.

McCammon, C.A., 1992. A new apparatus to conduct variable temperature high pressure Mössbauer spectroscopy. In: A.K. Singh (Editor), Recent Trends in High Pressure Research (Proceedings of the XIII AIRAPT International Conference on High Pressure Science and Technology). Oxford and IBL Publ. Co., New Dehli, 441 India, pp. 824-826.

443 McCammon, C.A. and Ross, N.L., 2003. Crystal chemistry of ferric iron in $444(\mathrm{Mg}, \mathrm{Fe})(\mathrm{Si}, \mathrm{Al}) \mathrm{O}_{3}$ majorite with implications for the transition zone. Physics and 445 Chemistry of Minerals, 30: 206-216. 
449 derived from high-pressure experiments. Earth and Planetary Science Letters, 222:

$450 \quad 435-449$.

McCammon, C., Kantor, I., Narygina, O., Rouquette, J., Ponkratz, U., Sergueev, I.,

453 Mezouar, M., Prakapenka, V. and Dubrovinsky, L., 2008. Stable intermediate-spin

454 ferrous iron in lower mantle perovskite. Nature Geoscience, 1: 684-687.

Ohta, K., Onoda, S., Hirose, K., Sinmyo, R., Shimizu, K., Sata, N., Ohishi, Y. and Yasuhara, A., 2008. The electrical conductivity of post-perovskite in Earth's D" layer. Science, 320: 89-91.

459

460

461

462

463

464

465

466

467

468

469

470

471

472

473

474

475

476

477

478

479

480

481

482

Rekhi, S., Dubrovinsky, L.S. and Saxena, S.K., 1999. Temperature-induced ruby fluorescence shifts up to a pressure of $15 \mathrm{GPa}$ in an externally heated diamond anvil cell. High Temperatures - High Pressures, 31: 299-305.

Rüffer, R. and Chumakov, A.I., 1996. Nuclear resonance beamline at ESRF. Hyperfine Interactions, 97/98: 589-604.

Schreinemakers, F.A.H., 1916. Invariant, monovariant and divariant equilibria.

Proceedings of the Academy of Science of Amsterdam, 19: 514-527.

Seda, T. and Hearne, G.R., 2004. Pressure induced $\mathrm{Fe}^{2+}+\mathrm{Ti}^{4+}->\mathrm{Fe}^{3+}+\mathrm{Ti}^{3+}$ intervalence charge transfer and the $\mathrm{Fe}^{3+} / \mathrm{Fe}^{2+}$ ratio in natural ilmenite $\left(\mathrm{FeTiO}_{3}\right)$ minerals. Journal of Physics-Condensed Matter, 16: 2707-2718.

Shvyd'ko, Y.V., 2000. MOTIF: Evaluation of time spectra for nuclear forward scattering. Hyperfine Interactions, 125: 173-188.

Stackhouse, S., Brodholt, J.P. and Price, G.D., 2007. Electronic spin transitions in iron-bearing $\mathrm{MgSiO}_{3}$ perovskite. Earth and Planetary Science Letters, 253: 282-290.

Umemoto, K., Wentzcovitch, R.M., Yu, Y.G. and Requist, R., 2008. Spin transition in $(\mathrm{Mg}, \mathrm{Fe}) \mathrm{SiO}_{3}$ perovskite under pressure. Earth and Planetary Science Letters, 276: 198-206. 
483

484 Wysession, M.E., Lay, T., Revenaugh, J., Williams, Q., Garnero, E., Jeanloz, R. and 485 Kellog, L., 1998. The D” discontinuity and its implications. In: M. Gurnis, M.E.

486 Wysession, E. Knittle and B.A. Buffet (Editors), The Core-Mantle Boundary Region, 487 Geodynamics Series 28. American Geophysical Union, Washington, DC, USA, pp. 488 231-253.

489 


\section{Figure Captions}

Figure 1. X-ray diffraction pattern of silicate perovskite at room temperature and 130 (5) GPa collected at the end of run \#3. The solid line through the data points indicates the fit derived from Rietveld refinement, and the line positions of $\mathrm{Au}$ (pressure marker), $\mathrm{CaCl}_{2}$-structured $\mathrm{SiO}_{2}$ (thermal insulator) and silicate perovskite with $\mathrm{Pbnm}$ space group are indicated by blue, red and black ticks, respectively.

Figure 2. Room temperature NFS spectra collected during run \#1: (a) majorite in air at $0 \mathrm{GPa}$; (b) majorite in DAC at $33 \mathrm{GPa}$; (c-e) sample transformed to silicate perovskite by laser heating. The pressures for the spectra are as follows: (c) $40 \mathrm{GPa}$; (d) $62 \mathrm{GPa}$; (e) $115 \mathrm{GPa}$. The red lines indicate the theoretical fit obtained using MOTIF.

Figure 3. Room temperature Mössbauer spectra collected for (a) majorite in air (run \#1); (b) majorite in the DAC (run \#2); (c) (d) silicate perovskite in the DAC (runs \#2 and \#3). The pressures for the spectra are as follows: (a) $0 \mathrm{GPa}$; (b) $61 \mathrm{GPa}$; (c) 125 $\mathrm{GPa}$; and (d) $130 \mathrm{GPa}$. The solid lines indicate the theoretical fit obtained using NORMOS, and the residual is indicated above each spectrum. The doublets are shaded as follows: high-spin $\mathrm{Fe}^{2+}$ (yellow); intermediate-spin $\mathrm{Fe}^{2+}$ (green); low-spin $\mathrm{Fe}^{2+}$ (blue); $\mathrm{Fe}^{3+}$ (red).

Figure 4. NFS spectra of silicate perovskite during run \#3 (at $\mathrm{P}=120 \mathrm{GPa}$ unless otherwise noted): (a) $\mathrm{T}=300 \mathrm{~K}$; (b) $\mathrm{T}=380 \mathrm{~K}$; (c) $\mathrm{T}=830 \mathrm{~K}$; (d) $\mathrm{T}=1000 \mathrm{~K}$; (e) P $=130 \mathrm{GPa}, \mathrm{T}=300 \mathrm{~K}$. The NFS spectrum in Fig. 4e was collected for the same sample at the same conditions as the Mössbauer spectrum in Fig. 3d. The red lines indicate the theoretical fit obtained using MOTIF.

Figure 5. Hyperfine parameter variation with pressure for majorite and silicate perovskite derived from room temperature NFS (squares) and Mössbauer (circles) spectra. The trends for individual species are linked by solid and dashed lines in their regions of stability and metastability, respectively, for high-spin $\mathrm{Fe}^{2+}$ in majorite (yellow); intermediate-spin $\mathrm{Fe}^{2+}$ in perovskite (green); low-spin $\mathrm{Fe}^{2+}$ in perovskite (blue) and $\mathrm{Fe}^{3+}$ (red). 
523 Figure 6. Proportion of low-spin $\mathrm{Fe}^{2+}$ relative to total $\mathrm{Fe}^{2+}$ in silicate perovskite as a

524 function of temperature at high pressure based on NFS (squares) and Mössbauer

525 (circles) spectra. The line joins the data for $120 \mathrm{GPa}$, while the pressures for the other

526 data points are indicated.

528 Figure 7. Proposed phase boundary for $(\mathrm{Mg}, \mathrm{Fe})(\mathrm{Si}, \mathrm{Al}) \mathrm{O}_{3}$ between perovskite $(\mathrm{pv})$ and 529 post-perovskite (ppv). The thick solid line indicates the phase boundary summarised

530 from data in the literature (Hirose, 2006), which may be shifted to higher pressures

531 due to an intermediate-spin (IS) to low-spin (LS) transition in the perovskite phase,

532 creating a region where silicate perovskite containing low-spin $\mathrm{Fe}^{2+}$ is stable (blue).

533 The region where IS $\mathrm{Fe}^{2+}$ is stable in the perovskite structure is shaded yellow, while

534 the region where IS $\mathrm{Fe}^{2+}$ is stable in the post-perovskite structure is shaded purple.

535 Symbols indicate the spin state determined for $\mathrm{Fe}^{2+}$ in silicate perovskite, where green

536 indicates intermediate spin and blue indicates low spin: large circles (this work); small

537 circle (McCammon et al., 2008); diamonds (Lin et al., 2008); squares (Badro et al.,

538 2004). The estimated depth range of the D" discontinuity is indicated by the black bar

539 (e.g., Wysession et al., 1998), and the green and blue dashed lines are a guide for the

540 eye.

542 Figure 8. The estimated thermal structure of D" adapted from Hernlund et al. (2005).

543 The perovksite to post-perovksite transition is shown by the thick solid (existing data)

544 and dashed (our proposed boundary) lines, and various geotherms are shown in red.

545 The region where IS $\mathrm{Fe}^{2+}$ is stable in the perovskite structure is shaded yellow, while

546 the region where IS $\mathrm{Fe}^{2+}$ is stable in the post-perovskite structure is shaded purple.

547 The blue region is where silicate perovskite containing low-spin $\mathrm{Fe}^{2+}$ would be stable,

548 which leads to the presence of post-perovskite lenses in cold regions (as already

549 proposed by Hernlund et al., 2005), but with intermediate-spin $\mathrm{Fe}^{2+}$ silicate perovskite 550 above and low-spin $\mathrm{Fe}^{2+}$ silicate perovskite below. 


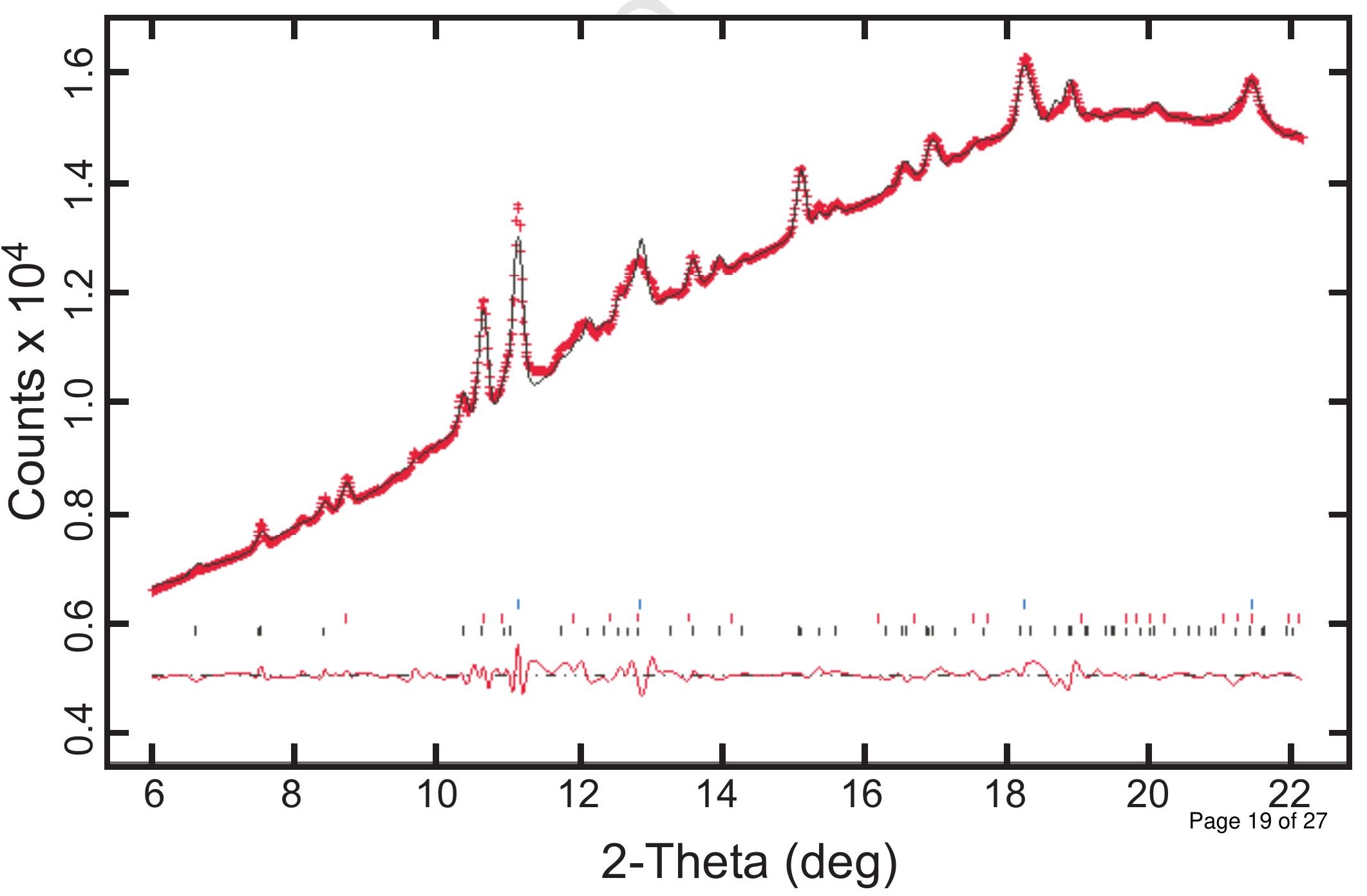




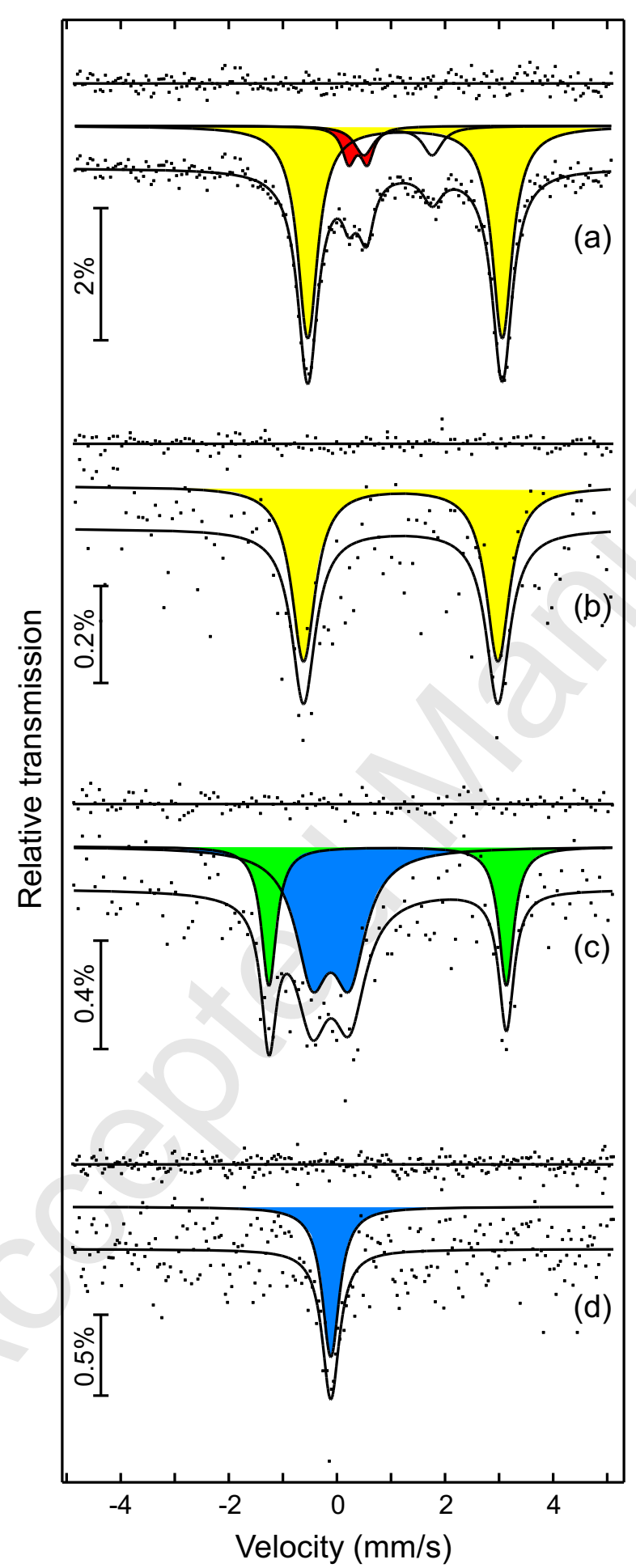




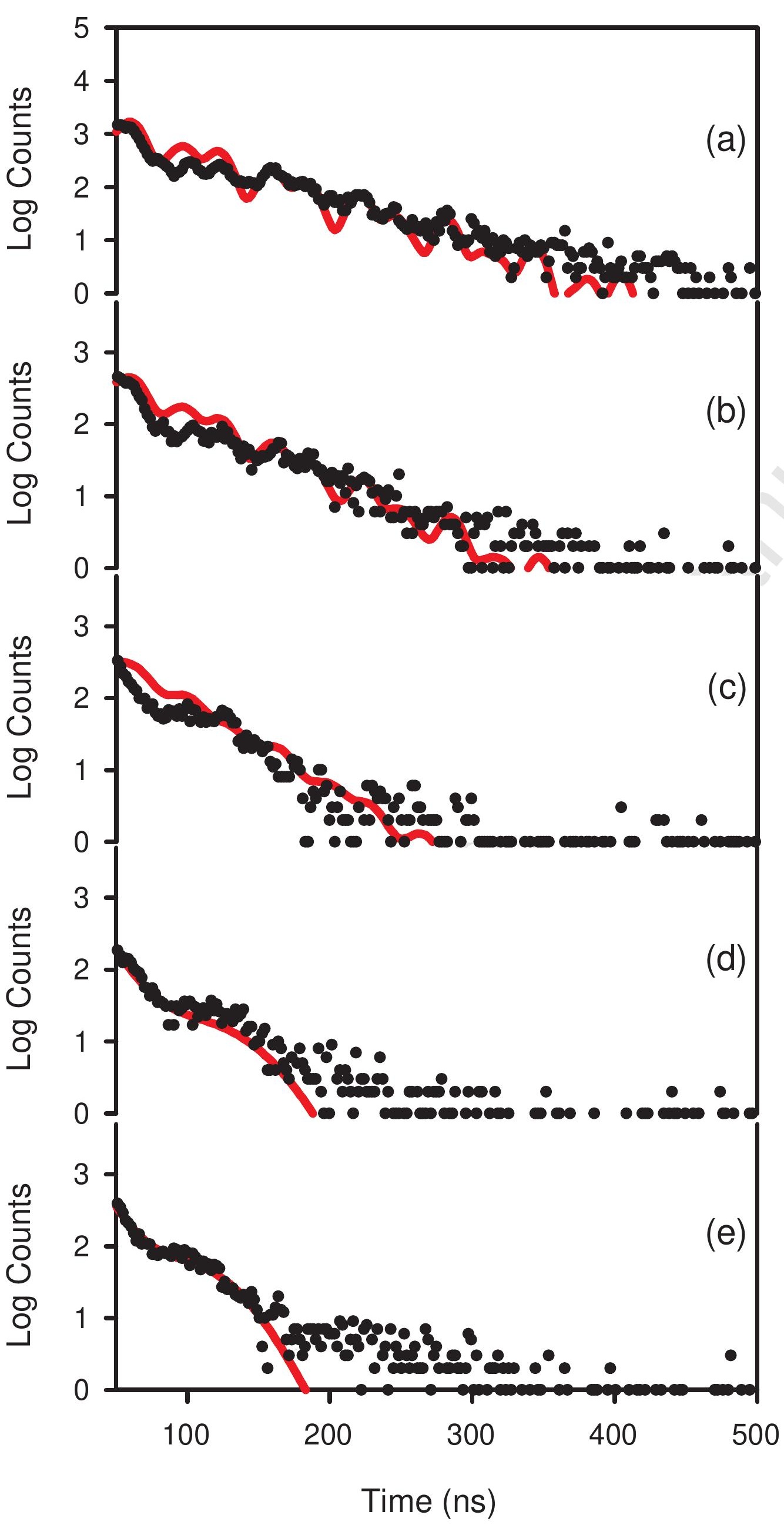

Page 22 of 27

Time (ns) 

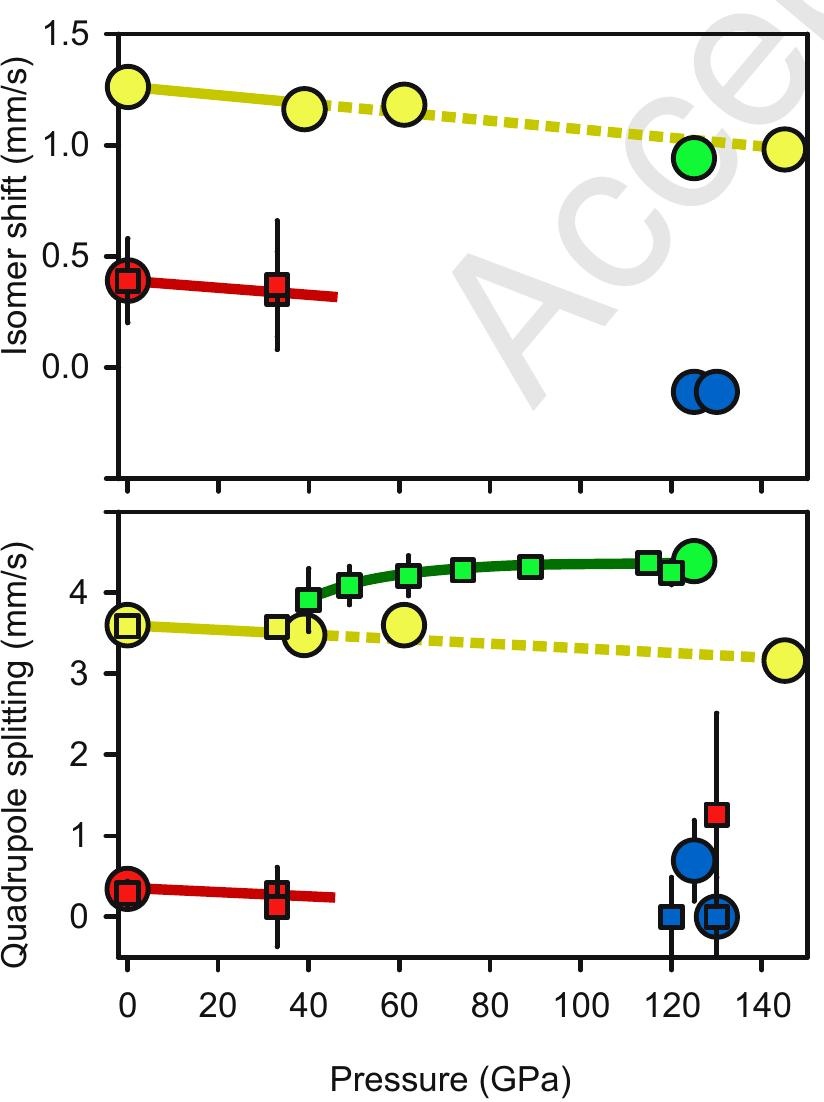

Page 23 of 27

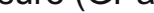




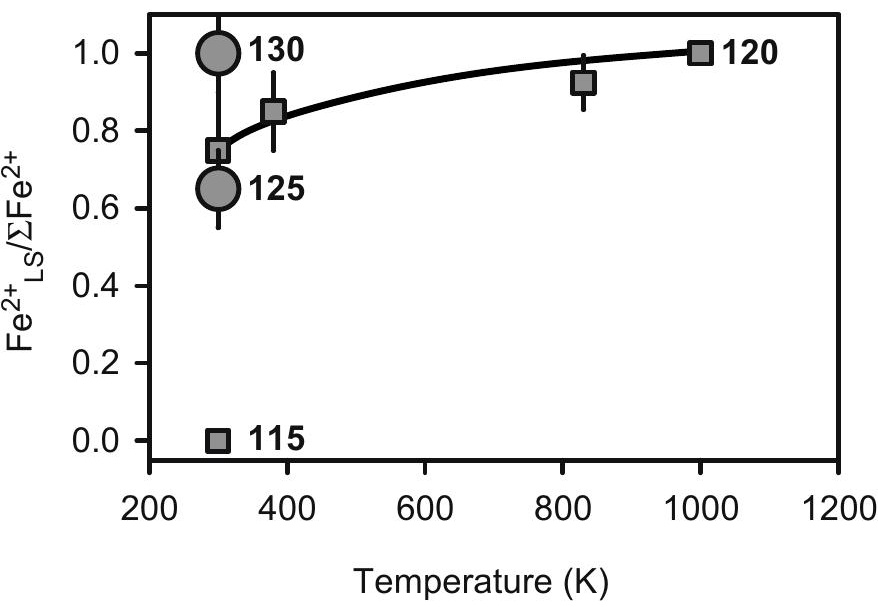

Page 24 of 27 位erature (n) 


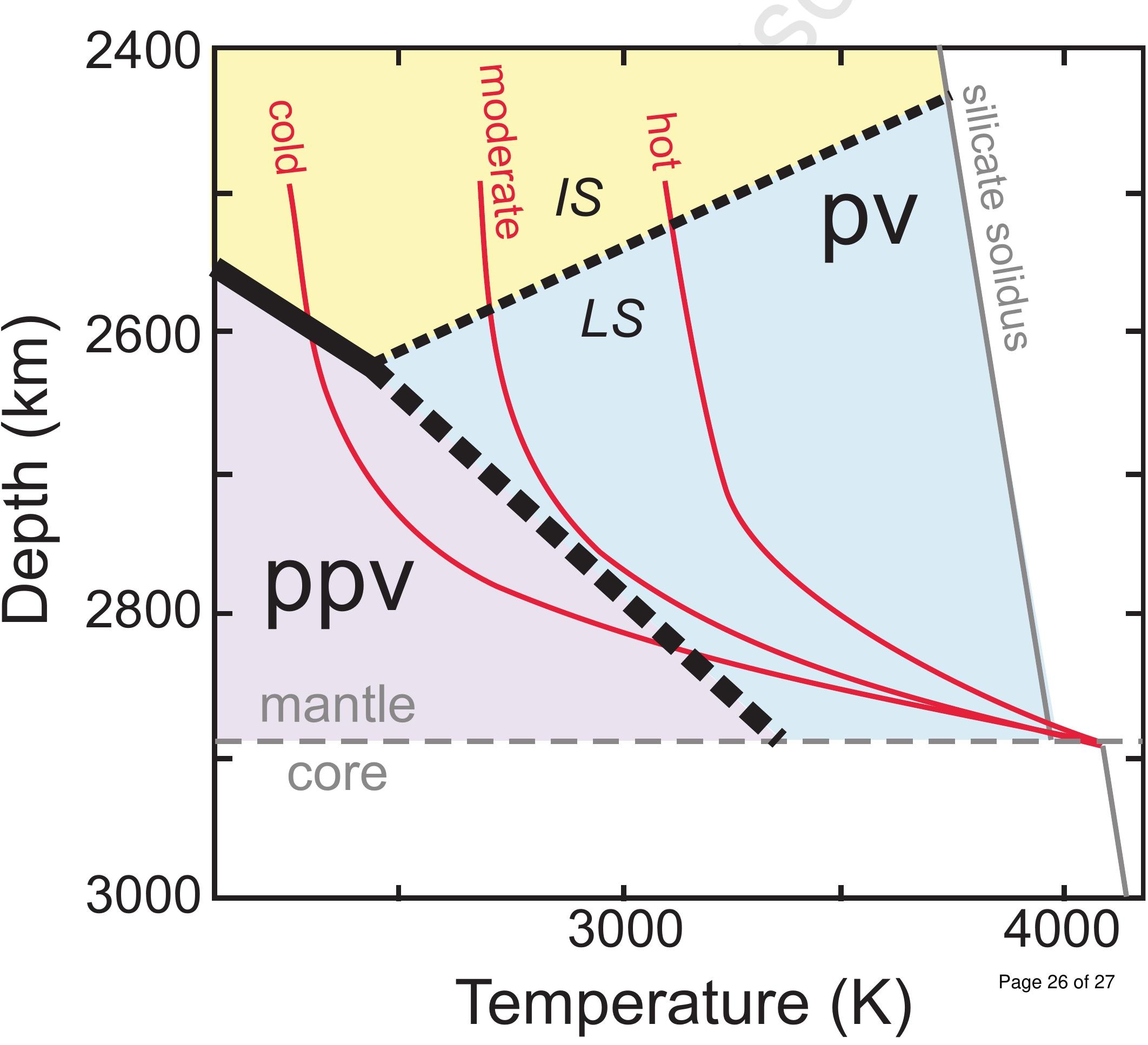

\section{Temperature (K)}

Page 26 of 27 
Table 1. Summary of run conditions and data collection

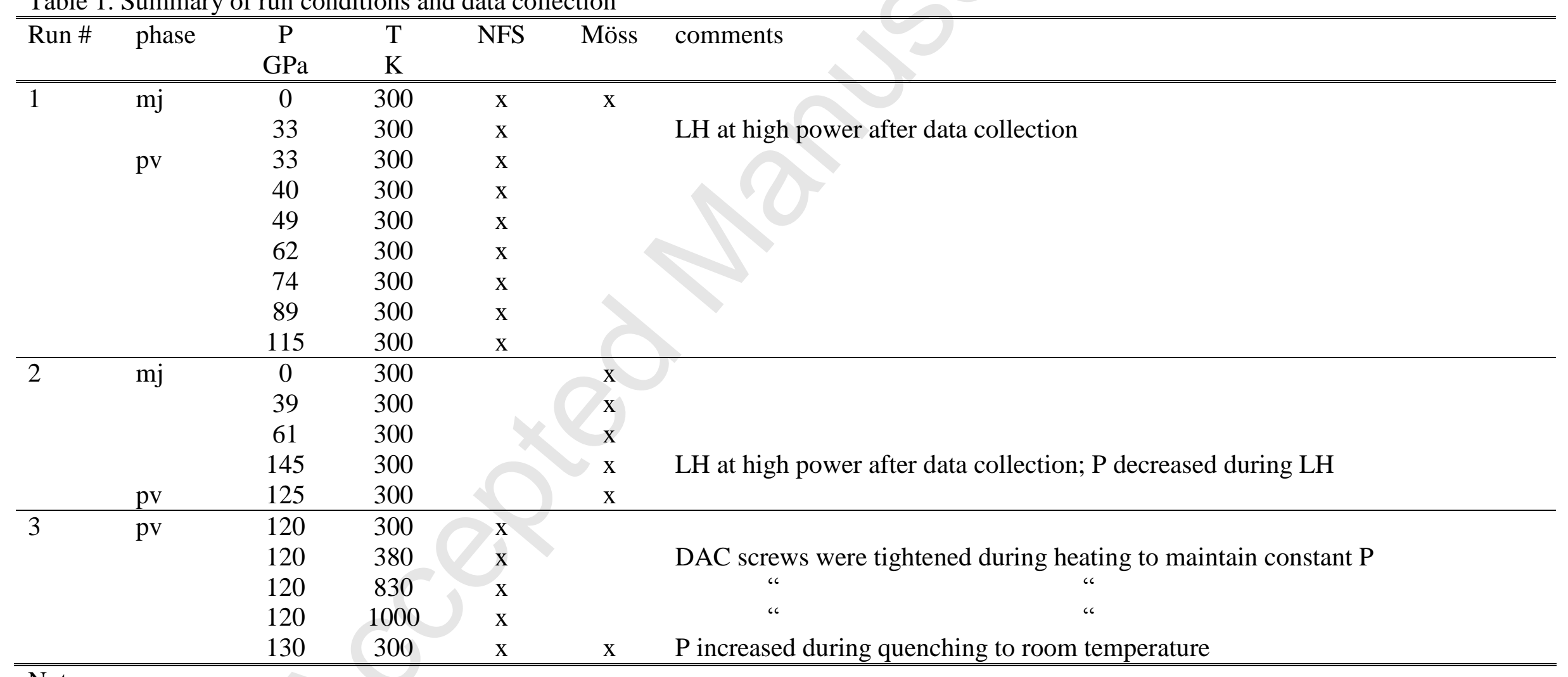

\section{Notes:}

mj: majorite; pv: perovskite; NFS: nuclear forward scattering; Möss: Mössbauer spectroscopy; LH: laser heating

During runs \#1 and \#2, the sample was annealed after each increase of pressure using an infrared laser at low power to relieve stress 